\title{
Dual stimuli-responsive dynamic covalent peptide tags: Towards sequence-controlled release in tumor-like microenvironments
}

Maksymilian M. Zegota, ${ }^{\nabla 1,2}$ Michael Andreas Müller, ${ }^{\nabla 1}$ Bellinda Lantzberg, ${ }^{1}$ Gönül Kizilsavas, ${ }^{1}$ Jaime A. S. Coelho, ${ }^{3}$ Pierpaolo Moscariello, ${ }^{1}$ María Martínez-Negro, ${ }^{1}$ Svenja Morsbach, ${ }^{1}$ Pedro M. P. Gois, ${ }^{4}$ Manfred Wagner, ${ }^{1}$ David Y. W. Ng, ${ }^{1}$ Seah Ling Kuan, ${ }^{*}{ }^{*}, 2$ Tanja Weil ${ }^{* 1,2}$ ${ }^{1}$ Max Planck Institute for Polymer Research, Ackermannweg 10, 55128 Mainz, Germany ${ }^{2}$ Institute of Inorganic Chemistry I, Ulm University, Albert-Einstein-Allee 11, 89081 Ulm, Germany

${ }^{3}$ Centro de Química Estrutural, Faculty of Sciences, University of Lisbon, Campo Grande, 1749-016 Lisbon, Portugal

${ }^{4}$ Research Institute for Medicines (iMed.ULisboa), Faculty of Pharmacy, University of Lisbon, 1649-003 Lisbon, Portugal

\begin{abstract}
Dynamic covalent chemistry ( $\mathrm{DCvC})$ has emerged as a versatile synthetic tool for devising stable, stimuli-responsive bioconjugates. The interplay of binding affinity, association and dissociation constants exhibits a strong influence on the selectivity of the reaction, the conversion rate, as well as the stability in aqueous solutions. Nevertheless, dynamic covalent interactions often exhibit fast binding in combination with fast dissociation events and vice versa. To overcome the intrinsic limitation, we have designed dynamic covalent peptide tags combining two different pairs of dynamic covalent interactions with different reaction kinetics: (1) the fast association of boronic acid and catechol that forms $\mathrm{pH}$-sensitive and rapidly dissociating boronate esters, and (2) the slower formation of a redox-active disulfide bond with slow dissociation rate. Pre-coordination of the thiols of the cysteine residues by the fast boronic acid-catechol interaction primarily yields the heterodimers proving selectivity and self-sorting
\end{abstract}


capability of the reaction, with improved complex stability in aqueous solution and even in the acidic tumor-like extracellular microenvironment. The resulting bis-peptide conjugate responds to $\mathrm{pH}$ changes within the physiological range as well as to a redox environment that is similar to certain conditions found inside cancer cells. We believe that such tags hold great promise, through cooperative effects, for controlling the stability of bioconjugates under dilution in aqueous media, as well as designing intelligent pharmaceutics that react to distinct biological stimuli in cellular environments.

Keywords: Cooperative dynamic covalent chemistry, sequence-controlled, dual responsive, bioconjugate, tumor microenvironment

\section{Introduction}

The development of smart therapeutics, e.g. bioconjugates and drug delivery systems that capitalize upon the biochemical and physical differences manifested by tumor and normal tissues, is of utmost importance to devise effective treatment options. ${ }^{1-3}$ For example, systems that exploit the acidic extracellular matrix, acidic intracellular endosomes, elevated temperature and higher glutathione concentrations found in cancer cells, have been designed to trigger drug release selectively. ${ }^{2,4}$ Nevertheless, the field is still fraught with challenges due to unsatisfactory systemic stability, poor tumoral penetration or premature drug release of most drug delivery systems. ${ }^{1,2}$ In particular, stimulus-responsive linker chemistry has emerged as a central tool for the design of smart therapeutics and bioconjugates that can respond to the microenvironment of diseased cells and tissue. In this regard, a fine balance between stability and reversibility, as well as sensitive response to small changes in the environmental parameters are required. Covalent bonds are employed to form stable products but cannot be cleaved so easily. On the other hand, supramolecular interactions provide responsiveness but often cannot allow for sufficient binding affinity and stability in complex cellular environments and under high dilution. ${ }^{5}$ Dynamic covalent reactions (DCvR) promise new avenues for providing orthogonality, as well as combining high stability with reversibility at physiologically relevant conditions. ${ }^{6,7}$ Ideally, the DCvRs should possess fast association (high on-rate, $k_{\text {on }}$ ) 
for rapid assembly and efficient conjugation at even at lower concentrations, as well as a slow dissociation (low off-rate, $k_{\text {off }}$ ) so that the conjugates remain stable upon dilution.

An example of DCvR exhibiting fast $k_{\text {on }}$ rates is based on phenylboronic acid chemistry..$^{8,9} 2$ Formylphenylboronic acid undergoes a quick, $\mathrm{pH}$-reversible ligation with $\mathrm{N}$-terminal cysteine to form thiazolidino boronate $\left(k_{\mathrm{on}} \sim 10^{3} \mathrm{M}^{-1} \mathrm{~s}^{-1}\right) .{ }^{10}$ This is comparable to one of the fastest known bioorthogonal reactions, i.e. inverse electron demand Diels-Alder (IEDDA) $\left(k_{\text {on }}>10^{3} \mathrm{M}^{-1} \mathrm{~s}^{-1}\right) \cdot{ }^{11}$ However, in contrast to the irreversible IEEDA reaction, the thiazolidino boronate can achieve $10 \%$ release at $\mathrm{pH}=5$ and $26 \%$ release at $\mathrm{pH}=4,{ }^{10}$ rendering it attractive for preparing responsive bioconjugates. Nevertheless, fast binding often has its price - either fast dissociation or lack of conjugate stability. Boronic acid condensations, i.e. with catechol groups, proceed with fast $k_{\text {on }}$ rates of about $10^{3} \mathrm{M}^{-1} \mathrm{~s}^{-1}$, but the resultant conjugates usually lack hydrolytic stability. ${ }^{8,9,12}$ Two peptide strands each containing up to three non-canonical boronic acid and catechol residues were shown to hybridize and the resultant double stranded peptide conjugates revealed low dissociation constants dependent on the number of interacting groups (the term hybridization is used in accordance with the process of joining two complementary strands of nucleic acids). However, the formed conjugates still suffered from fast dissociation. The reactions of boronic acid derivatives with the salicylhydroxamic acid also exhibit high binding affinity $\left(K_{D} \sim 10 \mu \mathrm{M}\right)$ but also here, fast dissociation was observed (estimated $k_{\text {off }} \sim 10$ $\left.{ }^{2} \mathrm{~s}^{-1}\right) \cdot{ }^{13,14}$ Gois and coworkers incorporated additional interactions through a N,O-bidentate ligand to lock the thiazolidino boronate boron atom by an additional boron-oxygen bond, which appeared to be remarkably stable with less than $20 \%$ hydrolysis for two days. ${ }^{15}$ However, long reaction times are required for bond formation ( $48 \mathrm{~h})$. Conversely, bioconjugates with dynamic covalent hydrazones/hydrazides, oximes ( $\mathrm{pH}$-responsive) and disulfides (redox responsive) bonds ${ }^{16-18}$ also showed slow association rates leading to prolonged reaction times and low conjugation yields. ${ }^{19,20}$ Moreover, due to the slow disulfide formation, side reactions such as homodimerization often occur and the reactions are not strictly orthogonal. ${ }^{21}$ Even though disulfide bond formation could be accelerated by using oxidants such as trans-3,4dihydroxyselenolaneoxide or $\mathrm{N}$-chlorosuccinimide, their low yields and excessive formation of 
side products such as asymmetrical disulfides ${ }^{22}$ still represent major limitations. Therefore, achieving fast association in combination with slow dissociation still represents an inherent limitation that has not been solved yet. ${ }^{15,23}$

Therefore, new design strategies are required that are based on two complementary DCvRs compensating each other's weaknesses. ${ }^{24}$ Scott and coworkers have investigated a DNAmimetic dynamic covalent system exploiting $\mathrm{pH}$ responsive BA-CA (fast) and hydrazinealdehyde (slow) interactions. ${ }^{25}$ In this way, they encode molecular information to achieve selective assembly of molecular ladders and grids from base-4-encoded oligo(peptoid)s. Nevertheless, a combination of two orthogonal dynamic covalent interactions with two different stimuli on a peptide scaffold, their kinetics and stabilities have not been studied yet. In particular, the combination of boronate esters and disulfides offer (1) fast pre-assembly due to high $k_{\text {on }}$ of the boronic acid - catechol interactions, which will convert intermolecular to intramolecular disulfide formation, thereby compensating the slow and unspecific reactivity of thiols to form disulfide bonds; (2) stabilization of the resultant boronate esters due to low $k_{\text {off }}$ of disulfide (Figures 1-2). The resultant dual responsive double stranded bis-peptides react to changes in $\mathrm{pH}$ or redox conditions, similar to that found in tumor microenvironments, which holds immense promise for controlled drug delivery applications.

We demonstrate that short peptide tags containing both cysteine $(\mathrm{C})$ and non-canonical amino acids with boronic acid $(\mathrm{B})$ and catechol $(\mathrm{O})$ residues on the complementary positions exhibit cooperative effects with dissociation features that can be dictated by rationale sequence programming (Figure 2). In addition, targeting peptides such as cell penetrating TAT derived from human immunodeficiency virus can be easily extended on the peptide backbone through solid phase synthesis, and the $\mathrm{N}$-terminal amine can be exploited to incorporate cargoes such as fluorescent dyes to form dual-responsive bioconjugates for drug delivery and bioimaging. 

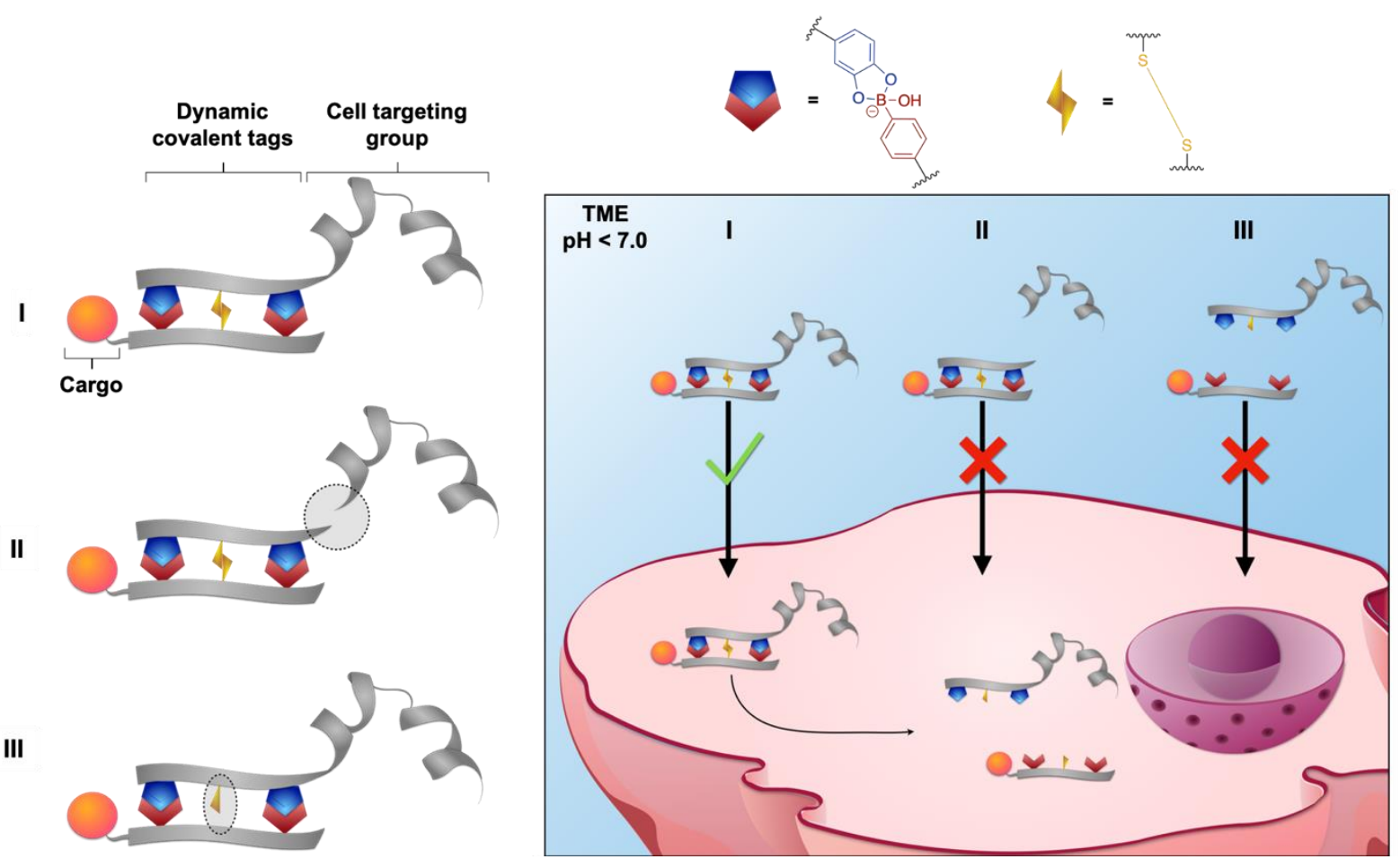

Figure 1: Conceptual overview of multivalent DCvRs based on cooperative boronic acid-catechol and thiol-thiol interaction imparting conjugate stability in the acidic tumor-like extracellular microenvironment as well as controlled release inside tumor cells.

\section{Results and discussion}

\section{Synthesis of Dynamic Covalent Peptide Tags}

Herein, four peptide sequences with varying boronic acid, catechol and cysteine motifs were designed. For clarity, new single letter codes were given for the non-canonical amino acids 4boronophenylalanine (B) and 3,4-dihydroxyphenylalanine (O), as depicted in Scheme 1. For solid-phase peptide synthesis (SPPS), the commercially available 4-boronophenylalanine (B) was protected in two steps with Fmoc and pinanediol on the amino and the BA functionality, respectively. ${ }^{26}$

To study the event of multiple boronic acid-catechol interactions, sequences with one or two $B$ and $O$ residues, as well as one cysteine $(C)$ per peptide were prepared, as shown in Scheme 1a and $1 \mathrm{~b}$. The polar amino acid serine (S) was selected as a short spacer that provides sufficient water-solubility with no charges to prevent potential electrostatic repulsion in the spacers in contrast to our previous studies using lysine as a spacer. ${ }^{26}$ All the sequences used in this investigation (BSC, OSC, BSCSB and OSCSO) and their oxidized heterodimers (10x, 20x) are shown in Scheme 1. The monomeric sequences were synthesized using standard 
Fmoc-SPPS with N,N'-diisopropylcarbodiimide/ethyl(hydroxyimino)cyanoacetate (DIC/Oxyma Pure®) coupling chemistry, purified using RP-HPLC (>95\% purity) and characterized by HR-ESI-MS and MALDI-TOF-MS (SI, Figures S1-S4).

In the following, we will use $\sim$ to symbolize dynamic covalent boronate ester formation of two complementary peptide strands in their reduced form ( $\mathbf{1}_{\text {Red }}$ and $\left.\mathbf{2}_{\text {Red }}\right)$, whereas $\simeq$ denotes hybridization of complementary peptide strands with boronate ester formation and thiol oxidation to form a disulfide bridge (10x and $\mathbf{2}_{\mathrm{ox}}$ ).

a)
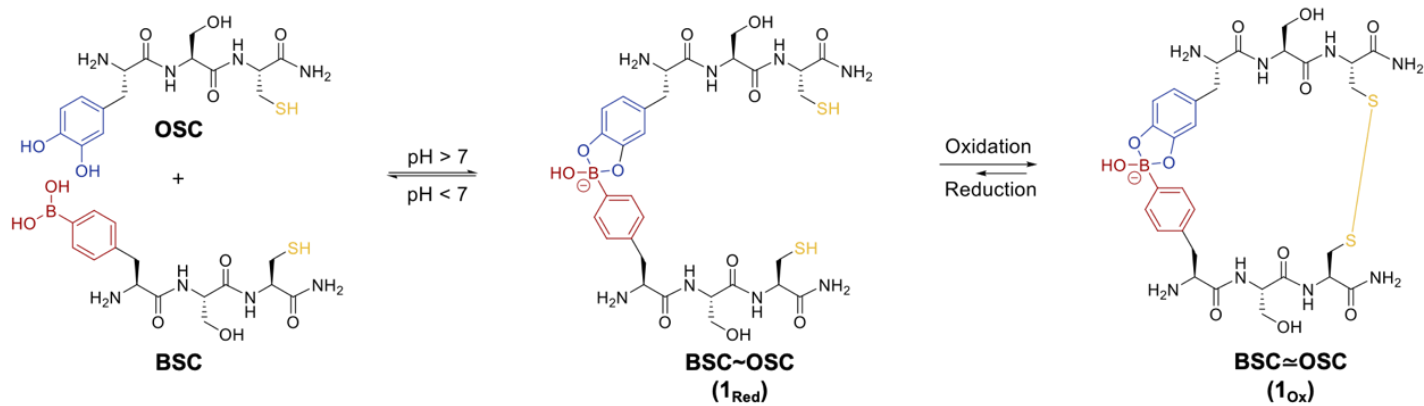

b)
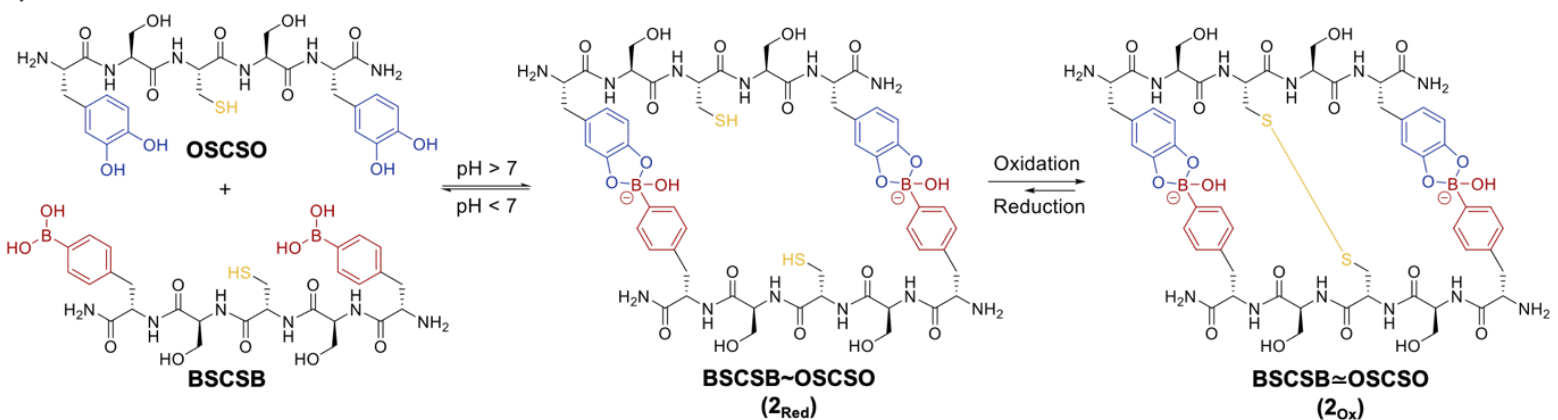

$\left(2_{0 x}\right)$

Scheme 1: a) Sequences of the tripeptide. b) Sequences of the pentapeptide. All amino acids are represented by single letter code: boronic acid (B), cysteine (C), serine (S) and catechol (O); denotes dynamic covalent boronate ester formation of B-O in two complementary peptide strands yielding $1_{\mathrm{Red}}$ and $2_{\mathrm{Red}}$ and $\simeq$ denotes both $\mathrm{B}-\mathrm{O}$ coordination and oxidation to form boronate ester and disulfide bridge formation leading to the dual stimuli-responsive peptide tags $10 x$ and $20 x$.

The hybridization conditions and the influence of $\mathrm{B}-\mathrm{O}$ pre-coordination on disulfide formation of complementary tags were first investigated using HPLC. The reaction conditions, i.e. molar ratio of potassium peroxymonosulfate $\left(\mathrm{Oxone}^{\circledR}\right)$, buffer strength and $\mathrm{pH}$, were optimized (SI, Figure S7). $100 \mathrm{mM}$ phosphate buffer (PB) at pH 7.4 and 1.8 mole equivalents of Oxone ${ }^{\circledR}$ were applied for disulfide formation in all subsequent experiments, if not mentioned otherwise (SI, Figure S7). Equimolar stock solutions (4000, 400 or $40 \mu \mathrm{M}$ in $100 \mathrm{mM}$ phosphate buffer, 
$\mathrm{pH}=7.4$ ) of complementary sequences were mixed in equal volumes and subsequently oxidized with Oxone ${ }^{\circledR}$ resulting in final concentrations of 2000,200 or $20 \mu \mathrm{M}$. Due to the sensitivity of the hybridization to $\mathrm{pH}$, it is important to adjust the $\mathrm{pH}$ of the solution after dissolution before the oxidation with Oxone ${ }^{\circledR}$. For all studies, hybridized sequences of $\mathbf{1}_{\text {Red }}$ and $\mathbf{2}_{\text {Red }}$ were prepared in situ by incubation of the individual components at $1 \mathrm{mM}$; while oxidation with Oxone ${ }^{\circledR}$ yield $\mathbf{1}_{\mathrm{ox}}$ and $\mathbf{2}_{\mathrm{ox}}$, as shown in the HPLC-chromatogram (Figure 2a). The reaction mixtures were immediately injected onto RP-HPLC. We observed less side products in the reaction mixture of the pentapeptides $\mathrm{BSCSB} \simeq$ OSCSO (2ox) versus the tripeptides BSC $\simeq$ OSC (10x). The incorporation of an additional boronic ester in $\mathbf{2}_{\mathrm{ox}}$ pair improves chemoselectivity by decreasing the amount of byproducts compared to 1ox (Figure $2 \mathrm{a}) .{ }^{27}$ Further analysis by LC-MS (Figure 2b) confirmed the formation of $\mathbf{1}_{\mathrm{ox}}$ and $\mathbf{2}_{\mathrm{ox}}$, with corresponding masses of 783 (1 $\mathbf{1}_{\mathrm{ox}}$, calc. $\left.\mathrm{m} / \mathrm{z}=782.65\right)$ and 1328 (2ox, calc. $\left.\mathrm{m} / \mathrm{z}=1326.97\right)$.

a)
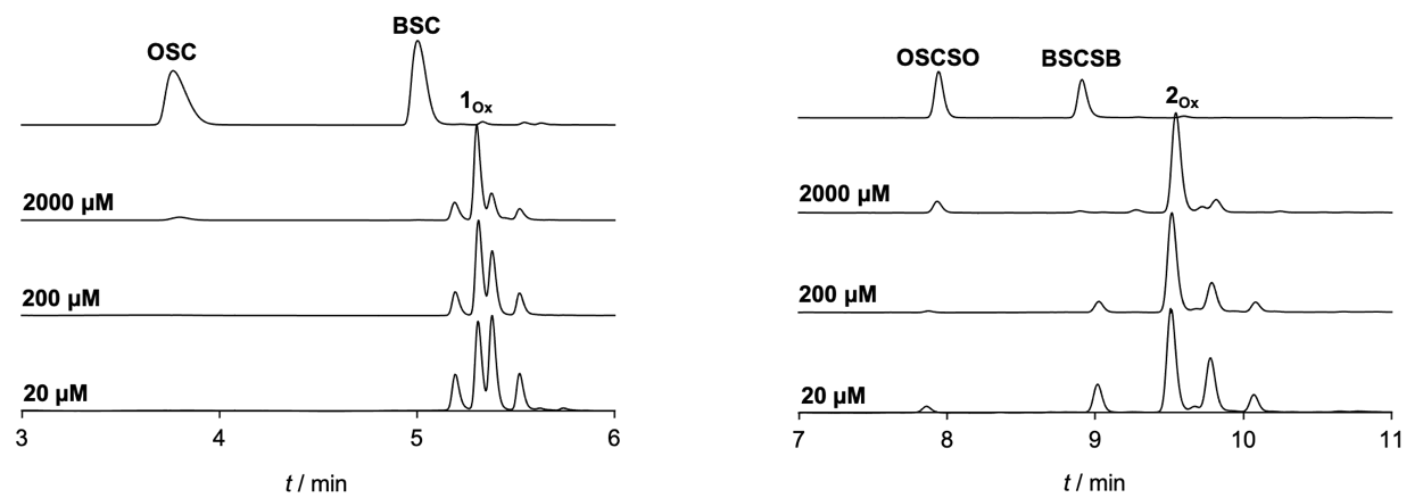

b)
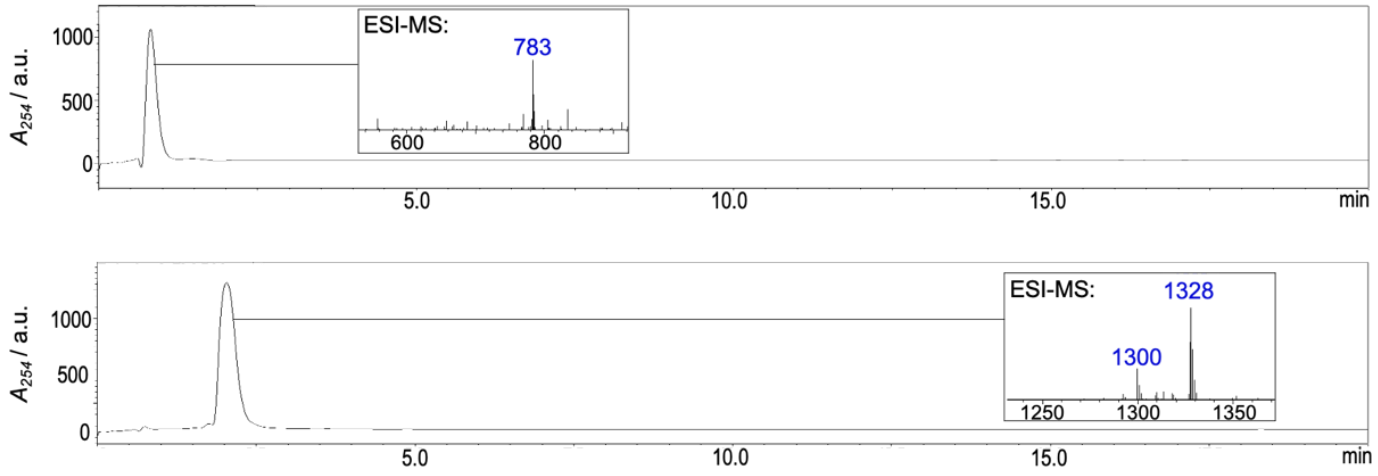

Figure 2: a) Chromatograms of oxidation reactions using tripeptides (left) and pentapeptides (right) with varying concentrations of binding partners. Reactions were performed in $100 \mathrm{mM}$ phosphate buffer $\mathrm{pH}=7.4$ by addition of 1.8 equivalent of potassium peroxymonosulfate. b) LC-MS analysis of $1_{\mathrm{ox}}$ (top, calc. $m / z=783.65[\mathrm{M}+\mathrm{H}]^{+}, \mathrm{measured} m / z=$ 783) and $20 x$ (bottom, calc. $m / z=1327.97[\mathrm{M}+\mathrm{H}]^{+}$, measured $m / z=1328$ ). 
The benefit of the pre-coordination on disulfide formation of $B S C \simeq O S C$ (10x) and BSCSB $\simeq$ OSCSO $(20 x)$ is the most pronounced at $2000 \mu \mathrm{M}$ but it can be also seen at lower concentrations (200 and $20 \mu \mathrm{M}$ ). In case of $20 x$, only few side products have been formed most likely due to higher percentage of fraction bound compared to 1ox. Based on the HPLC investigation, which showed conversion rates of aprox. $25 \%$ for $\mathbf{1}_{\mathrm{ox}}$ and up to $70 \%$ for $\mathbf{2}$ ox, peptide complex $2_{0 x}$ was selected for upscaling and used for all subsequent studies, including NMR studies to assess the structural parameters of the hybridization reaction and the obtained product.

Structural Analysis of Hybridized Tags by NMR and DFT Calculations. The structure and coordination of the hybridized peptide tags, in comparison to the single stranded peptide sequences, as well as oxidized form 2 ox were investigated by a combination of 1 - and 2dimensional NMR spectroscopy (Figure 3). 1D- ${ }^{1} \mathrm{H}-\mathrm{NMR}$ shows changes in the entire chemical environment upon boronic acid-catechol (B-O) conjugation in both $\mathbf{2}_{\text {Red }}$ and $\mathbf{2}$ ox (Figure $3 \mathrm{~b}$, Figure S12). We observed minor impurities in both spectra (Figure 3b), presumably due to homodimers and over-oxidized species, which were also observed in HPLC (Figure 2a). The most affected regions are the $\mathrm{H}_{\alpha}$ and the $\mathrm{H}_{\beta}$ protons of the respective cysteines, phenyl boronic acids and catechol (Figure 3c), as well as the aromatic side chain regions, which is clearly shown in the homonuclear total correlation spectroscopy (TOCSY) derived spectra for $\mathbf{2}_{\text {Red }}$ (Figure 3d). Upon conjugation, there is a change in the electron density around the protons of both peptides BSCSB and OSCSO, as mirrored in the chemical shift difference in the spectra. With the conformational change upon binding, protons of the amino acids in the proximity of boronic acid and catechol are brought to a position with a deshielding or shielding effect of the "shielding cones", resulting in a downfield or upfield shift, respectively. The aromatic signals as well as the $\mathrm{H}_{\alpha}$ and $\mathrm{H}_{\beta}$ signals of the cysteines show an upfield shift, indicating shielding effects (black arrows, Figure $3 c$ and Figure 3d). On the other hand, a region with an inverse effect, i.e. a downfield shift, was also observed (red arrow, Figure 3c) corresponding to the $\mathrm{H}_{\alpha}$ and $\mathrm{H}_{\beta}$ protons of the terminal amino acids in the sequence of each peptide bearing the boronic acid or catechol moieties. Complexation of the complementary peptides (2 mM) was further 
substantiated by diffusion ordered NMR (DOSY), where slower diffusion of the complex $\left(3.4 \cdot 10^{-10} \mathrm{~m}^{2} \mathrm{~s}^{-1}\right)$ was observed in comparison to the single peptide $\left(3.6 \cdot 10^{-10} \mathrm{~m}^{2} \mathrm{~s}^{-1}\right)$ suggesting an increase of the hydrodynamic radius (SI, Figure S13). The formation of the disulfide was proven by HPLC analysis and discussed in the subsequent section (Figure $5 d$ ).

a)

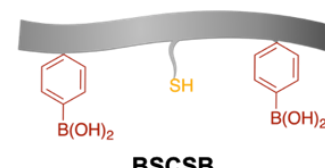

BSCSB

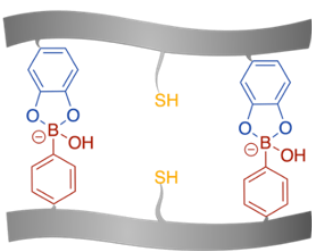

$2_{\text {Red }}$

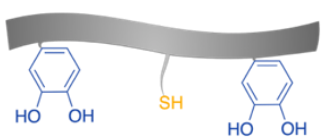

oscso

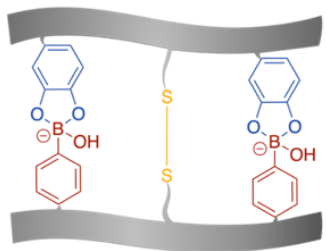

$2_{0 x}$ b)

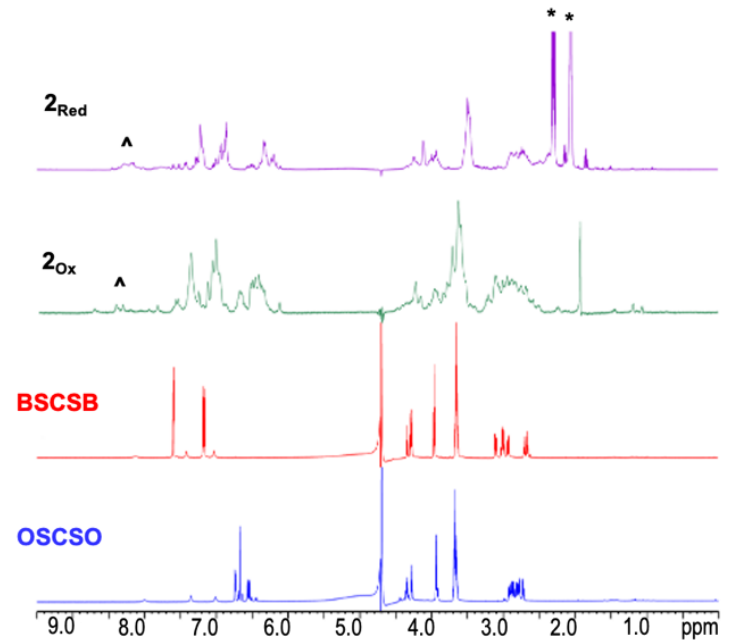

e)
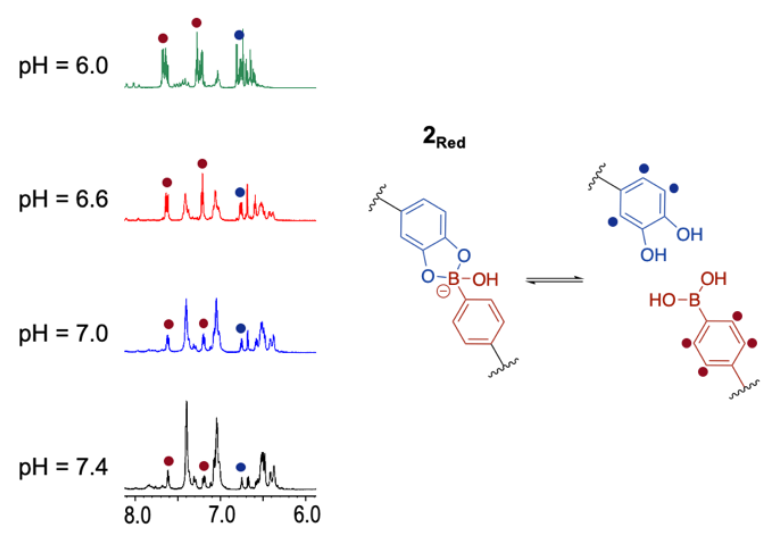

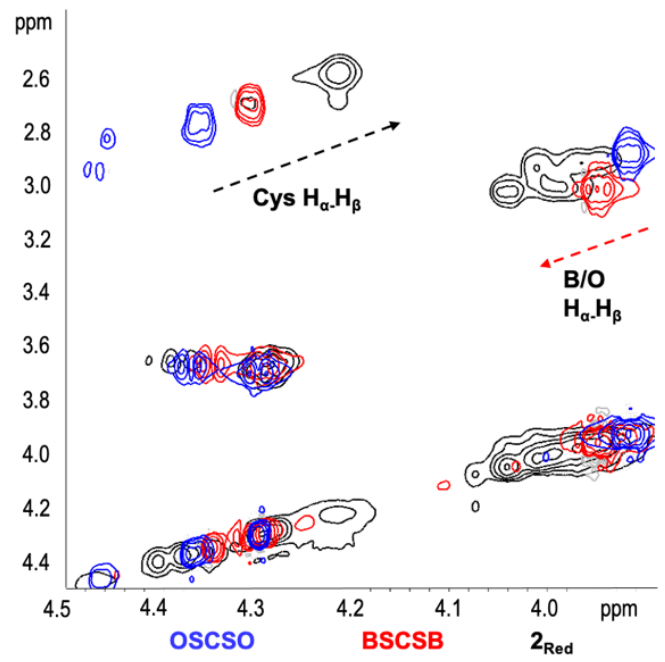

d)

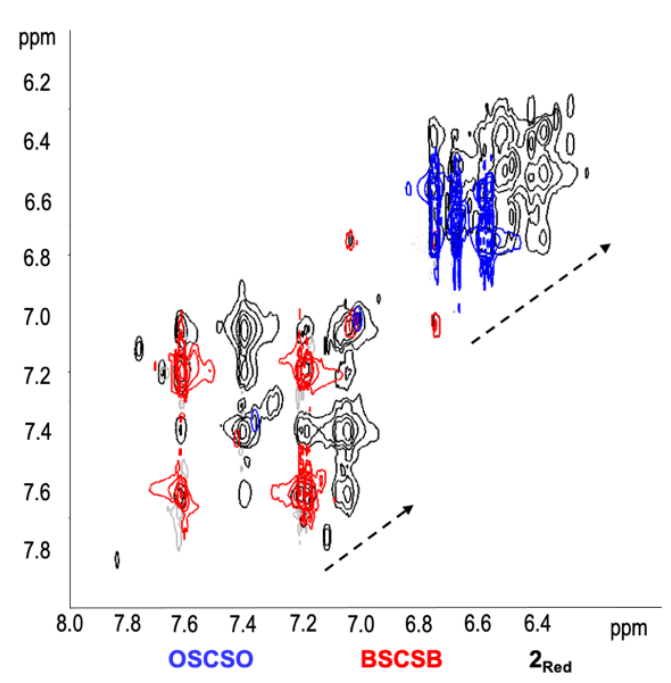

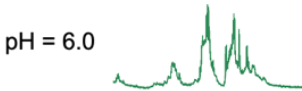
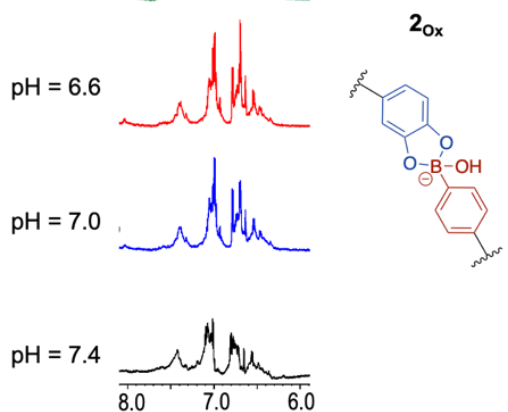

Figure 3: a) Simplified scheme of the monomers as well as $2_{\text {Red }}$ and $2_{0 x}$. b) 1 H-NMR for peptide monomer and the hybridized double stranded peptide conjugate in reduced ( $2_{\text {Red }}$ ) and oxidized (20x) form in $300 \mathrm{mM}$ phosphate buffer, pH 
7.4, $10 \%$ D2O in $\mathrm{H} 2 \mathrm{O}$. * denotes signals due to the reducing reagent TCEP; ^ are due to minor impurities, presumably due to homodimers and oxidized species. c, d) ${ }^{1} \mathrm{H}-{ }^{1} \mathrm{H}$ TOCSY for single peptides and $2_{\text {Red }}$ in 300 mM phosphate buffer, $\mathrm{pH} 7.4,10 \% \mathrm{D}_{2} \mathrm{O}$ in $\mathrm{H}_{2} \mathrm{O}$ (full ${ }^{1} \mathrm{H}-{ }^{-1} \mathrm{H}$ TOCSY spectrum and the signal assignment for BSCSB and OSCSO available in the

SI, Figures S11 and S12). e) pH dependent chemical shifts of the aromatic protons in reduced and oxidized form.

To gain further structural information of the peptide sequences and the oxidized conjugate $\mathbf{2}_{\mathrm{ox}}$, density functional theory (DFT) calculations were performed at M06-2X/def2TZVPP/PCM(SMD,water)//B3LYP/6-31G(d) level of theory (Figure 4). The low-lying energy structures of the single peptides (BSCSB and OSCSO) are found to be relatively compact and stabilized by multiple intramolecular hydrogen bonds (SI, Figures S17-18). Binding entails a linearization of the sequences through formation of the boronate esters, a disulfide bond and intramolecular hydrogen bonds between BSCSB and OSCSO (SI, Figure S19-20), which heavily influence the chemical environment of the nearby protons - consistent with both the results from ${ }^{1} \mathrm{H}$ and multidimensional NMR.

Furthermore, calculations suggest that the anti-parallel binding (Figure $4 \mathrm{~b}, \mathrm{~N}$-termini on the opposite sides of the conjugate) is favored over the parallel binding (Figure $4 \mathrm{~b}, \mathrm{~N}$-termini on the same side), with a Gibbs free energy difference of $3.5 \mathrm{kcal} \mathrm{mol}^{-1}$. To further understand the preference for the antiparallel topology, a distortion/interaction analysis was performed (SI, Figure S21). This analysis reveals stronger overall non-covalent interactions between BSCSB and OSCSO for the antiparallel binding that overpowers the higher degree of distortion of the single peptides in this binding mode. Finally, to study the influence of bulky substituents at the $\mathrm{N}$-termini of the peptides on the formed hybridized structures, calculations were performed with an additional simplified model analogue comprising of a positively charged RGD sequence on OSCSO and a negatively charged fluorescein dye coupled to the N-termini of the BSCSB sequence (Figure 4c). Once again, the antiparallel binding was determined to be the most favored with a Gibbs free energy difference of $7.5 \mathrm{kcal} \mathrm{mol}^{-1}$. This greater difference is attributed to further electrostatic interactions from the positively charged guanidine RGD and the negatively charged dye (SI, Figure S22-23), suggesting that electronic factors play a role in the arrangement of the peptide sequences. 
a)
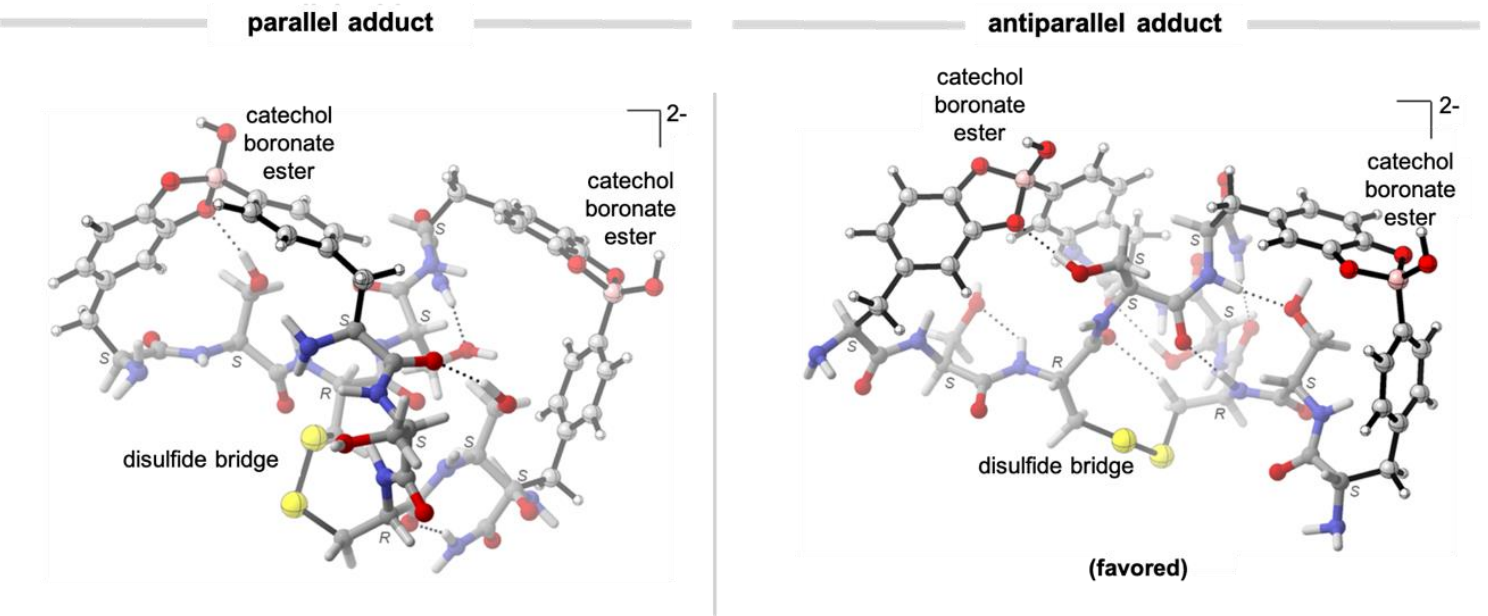

b)
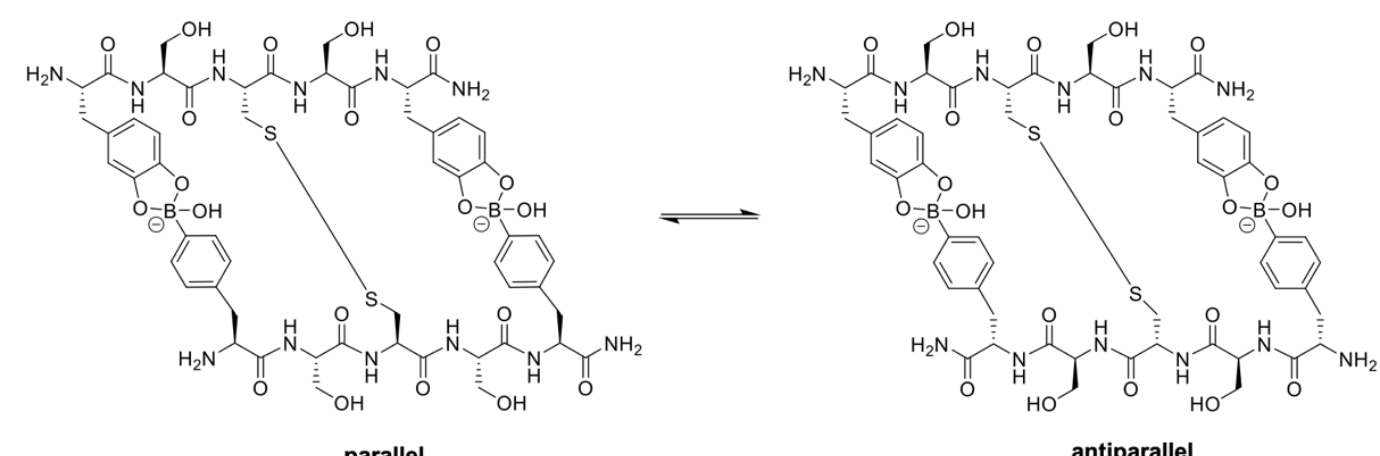

c)

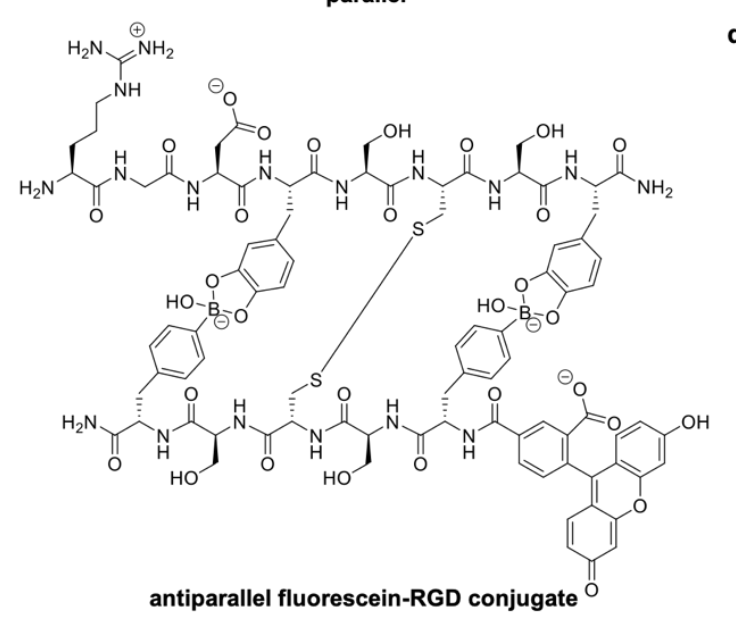

d)

\begin{tabular}{|c|c|}
\hline Complex & Thermodynamic Parameters \\
\hline BSCSB $\simeq$ OSCSO $\left(2_{0 x}\right)$ & $\Delta \Delta G=3.5 \mathrm{kcal} \mathrm{mol}^{-1}$ \\
\hline Fluorescein $\simeq$ RGD & $\Delta \Delta G=7.5 \mathrm{kcal} \mathrm{mol}^{-1}$ \\
\hline
\end{tabular}

Figure 4: a) DFT optimized structure of parallel and antiparallel 2ox at B3LYP/6-31G(d) theory level (color coding: gray carbon, white - hydrogen, red - oxygen, blue - nitrogen, yellow - sulfur, pink - boron). Chemical structures of (b) 2 ox in the parallel and antiparallel conformation as well as (c) the antiparallel fluorescein-RGD are given.

d) Thermodynamic parameters from DFT analysis.

Structural NMR Analysis of the Dynamics of Hybridized Tags. Next, the effects of both $\mathrm{pH}$ and redox conditions on the hybridized sequences were studied using $\mathbf{2}$ ox and $\mathbf{2}_{\text {Red }}$ utilizing ${ }^{1} \mathrm{H}-\mathrm{NMR}$ spectroscopy. ${ }^{1} \mathrm{H}-\mathrm{NMR}$ spectra of $\mathbf{2} \mathrm{ox}$ are essentially the same in all cases, regardless of the $\mathrm{pH}$ range from 6.0 to 7.4 (Figure $5 \mathrm{e}$ ). The only difference is the appearance of signals between 8.0 and 8.5 ppm, which belong to the amide backbone and is based on the acidity change and thus on the decreased proton exchange rate with the bulk water (Figure 5e). In 
contrast, under reductive conditions, in the presence of tris(2-carboxyethyl)phosphine (TCEP), the thiol groups are free, and the conjugate is bound only through $\mathrm{pH}$ sensitive boronate esters. Decreasing the $\mathrm{pH}$ affects the signals originating both from side chains and the backbones (Figure 5e) that split to eventually result in a spectrum resembling simple overlap of single peptides spectra (SI, Figure S5). Nevertheless because of the high concentration, which was about three orders of magnitude above the dissociation constant, complete dissociation into the monomers at $\mathrm{pH} 6$ did not occur. Therefore, additional studies were performed under conditions mimicking the tumor microenvironment.

\section{Dual-Stimuli Responsiveness of the Dynamic Covalent Tags in the Presence of Stimuli}

of the Tumor Microenvironment. Next, we further investigated and confirmed the interactions of boronic acid and catechol groups, the formation of disulfides, as well as the reversibility of the bis-peptide system (Figure 5). First, the boronic acid condensation with the complementary catechol and the thermodynamic properties were assessed. Thus, we applied equimolar concentrations of the reacting tags to investigate the thermodynamic parameters associated with the formation of the heterodimer. DyLight488 labeled peptide (DL488-BSCSB) was synthesized by connecting the commercially available NHS-ester of this dye to the $\mathrm{N}$-terminus of the BSCSB sequence to enable a microscale thermophoresis (MST) experiment, in which the dissociation constant could be determined. MST measurements were performed by titrating DL488-BSCSB $(2 \mu \mathrm{M})$ against the complimentary OSCSO peptide binding partner $(76 \mathrm{nM}-5 \mathrm{mM})$. A dissociation constant in the low micromolar range $\left(K_{D}=1.8 \pm 0.4 \mu \mathrm{M}\right.$, Figure 5b) was obtained for DL488-BSCSB OSCSO at $\mathrm{pH}=7.4$, which was one order of magnitude lower than the previously reported divalent analogue KOKOK KBKBK $\left(K_{D}=80.0 \pm 7.0 \mu \mathrm{M}\right)^{26}$ and three orders of magnitude lower than the single phenylboronic acid - catechol interaction $\left(K_{D}=1.2 \mathrm{mM}\right) \cdot{ }^{28}$ Such an improvement could be explained by the lack of electrostatic repulsion due to the presence of the electroneutral serine (at physiological $\mathrm{pH}$ ) in the sequence. To demonstrate $\mathrm{pH}$ responsiveness of the bioconjugate, the $\mathrm{pH}$ was adjusted to $\mathrm{pH} 6$, which drastically increased the $K_{D}$ to over $440 \mu \mathrm{M}$. To assess the binding constant at physiological $\mathrm{pH}$, isothermal titration calorimetry (ITC) measurements 
were performed. The raw data were plotted as heat rate versus time at $\mathrm{pH}=6$ and 7.4. (SI, Figure S8). From the independent binding model fit resulting of the integrated heat (Figure 5c), the thermodynamic parameters of interaction were obtained. At $\mathrm{pH}=6$ the heat of dilution (BSCSB to buffer) was similar to the reaction titration (BSCSB to OSCSO) indicating lack of binding. At $\mathrm{pH}=7.4$, significant exothermic signals were obtained, yielding a binding constant $K_{D}=1.8 \pm 0.4 \mu \mathrm{M}$, similar to the one previously determined by MST. Additionally, the reaction stoichiometry $n=1.2 \pm 0.1$ indicates that primarily $1: 1$ complexes were formed. It is noteworthy that we are able to maximize reaction mass efficiency by using equimolar concentrations of reagents in these studies, in contrast to literature, where a large excess of one of the reagents is usually applied to improve the conversion. ${ }^{29}$

After pre-coordination based on the boronic acid - catechol interaction, $\mathbf{2}_{\text {Red }}$ can be selectively oxidized to $20 x$ by forming a disulfide bridge (Figure 5a). We expect that this secondary S-S dynamic covalent bond locks the conjugate as a heterodimer introducing a reductive environment as a new stimulus for dissociation. Therefore, dissociation and formation of the disulfide was also confirmed by RP-HPLC by subjecting $1 \mathrm{mM}$ solutions of $\mathbf{2}_{\mathrm{ox}}$ and $\mathbf{2}_{\text {Red }}$ to reductive and oxidative conditions, respectively, and the peptide monomers were used as control (Figure $5 d$ ). Directly after the addition of Oxone ${ }^{\circledR}$ to the $\mathbf{2}_{\text {Red }}$ sample solution in PB, we "locked" the bis-peptide to form 20x with a retention time higher than any of its single constituents (Figure $5 \mathrm{~d}$ ). A solution of $20 x$ formed by oxidizing $\mathbf{2}_{\text {Red }}$ could be reduced subsequently by addition of the reducing agent TCEP, in solid form and slight excess, resulting in the complete hydrolysis of the bis-peptide into the monomeric peptide sequences (BSCSB and OSCSO) under acidic conditions (Figure $5 \mathrm{~d}$ ). This is because conjugate $\mathbf{2}_{\text {Red }}$ is formed in the presence of the reducing agent TCEP but is unstable under acidic conditions of the measurement where the eluent contains additive of $0.1 \%$ trifluoroacetic acid (TFA). Therefore, $\mathbf{2}_{\text {Red }}$ hydrolyzed to afford BSCSB and OSCSO. Taken together, our results showed cooperative effects of combining two DCvCs in a single tag and that the tags exhibit reversible behavior depending on $\mathrm{pH}$ and redox conditions. 
a)

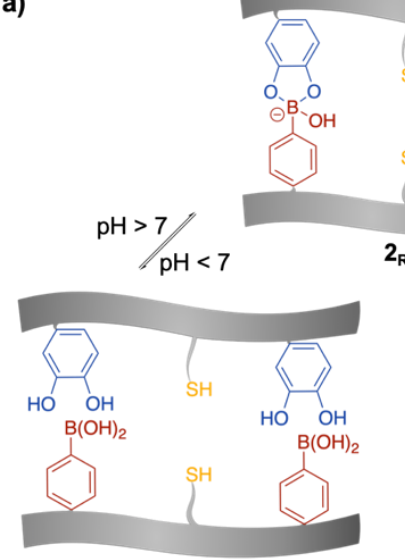

c)

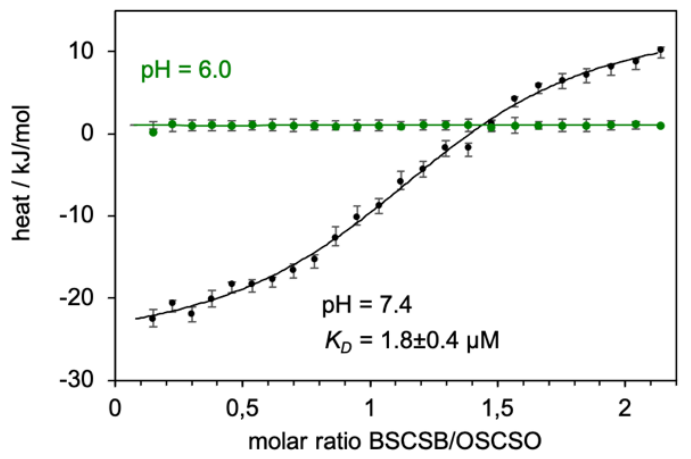

b)

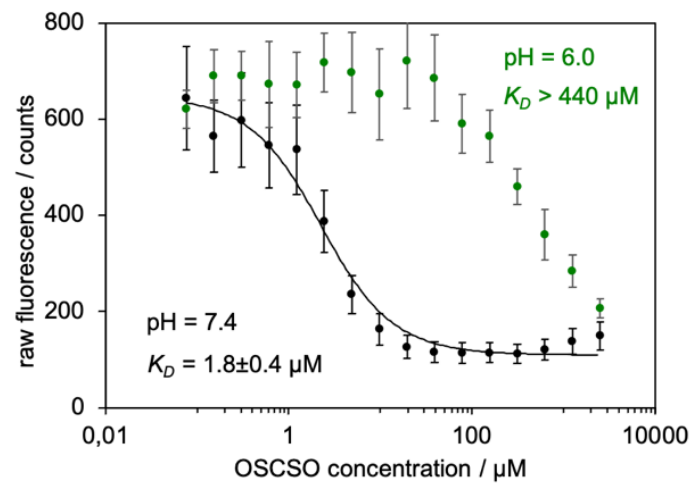

d)

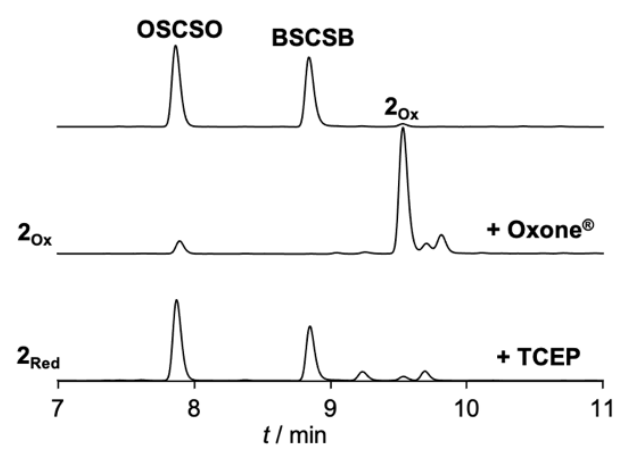

Figure 5: a) Formation of $20 x$ and $2_{\text {Red }}$ and reversibility of the reactions. b) Fluorescence quenching assay conducted in $100 \mathrm{mM}$ phosphate buffer both at $\mathrm{pH} 7.4$ and 6.0 in presence of TCEP. c) ITC binding curves showing integrated heats together with an independent binding model fit of $2_{\text {Red }}$ in $100 \mathrm{mM}$ phosphate buffer at $\mathrm{pH} 7.4$ and $\mathrm{pH}$ 6.0. d) Reversibility of disulfide bond formation with HPLC analysis ( $0.1 \%$ trifluoroacetic acid).

\section{Application of Cooperative Dynamic Covalent Tags under Conditions Mimicking the}

\section{Tumor Microenvironment}

Peptides often reveal low stability in cell media. Moreover, supramolecular interactions provide responsiveness but often cannot allow for sufficient binding affinity and stability in complex cellular environments and under high dilution. ${ }^{5}$ Therefore, we investigated the stability of $20 x$ in biologically relevant environment. First, serum stability of $2_{\mathrm{ox}}\left(1 \mathrm{mg} \mathrm{mL}^{-1}, 0.75 \mathrm{mM}\right)$ was assessed by the RP-HPLC-MS in $1 \times$ phosphate buffer saline (PBS) with $10 \%$ fetal calf serum (FCS) at $37^{\circ} \mathrm{C}$ and by applying Fmoc-Phe-OH as an internal standard (SI, Figure S8). The eluent was acidified with formic acid to exclude the influence of $\mathrm{B}-\mathrm{O}$ binding. Under these conditions, the conjugate remained stable for up to two days and started to decay over the course of $3-5$ days (Figure 6a), most likely due to disulfide exchange with cysteine-rich FCS. 
Thereafter, we tested the stability under conditions mimicking the tumor microenvironment, where it has been reported that cancer cells possess higher intracellular concentrations of glutathione (GSH/GSSG) in the cytosol, e.g. up to 10:0.25 mM in A549 lung carcinoma cells, compared to concentrations in healthy cells $(1: 0.025 \mathrm{mM}){ }^{30,31}$ The difference in the physiological concentration of GSH has been exploited for controlled release. Thus, the GSHinduced cleavage of $1 \mathrm{mM}$ of 2 ox was probed by incubation in commercially available liver cytosols spiked with physiologically relevant concentrations of GSH:GSSG (1:0.025 and 10:0.25 mM). The analysis was performed for up to $60 \mathrm{~min}$ and quantitative analysis was obtained using single ion monitoring (SIM) in LC-MS. Fmoc-Phe-OH was used as an internal standard (SI, Figure S9). The SIM mode improves limit of detection over UV-VIS detection by detecting ions towards specific $m / z$ of $20 x(m / z=1328,664)$. As shown in Figure $6 b$, the complex was partially reduced when incubated with $1 \mathrm{mM} \mathrm{GSH}$ and an equilibrium state was established after approximately $10 \mathrm{~min}$, with $80 \%$ of 2 ox unreacted. On the other hand, at a concentration of $10 \mathrm{mM}$ (molar ratio 10:1) the reaction was slightly slower due to longer equilibration time. However, it is apparent that after $60 \mathrm{~min}$, nearly all $20 x$ was cleaved to the peptide monomers, BSCSB and OSCSO. Therefore, although the oxidized complex is stable over a longer period in serum (Figure 6a), GSH release could be induced in cytosolic conditions in cancer cells (Figure 6b), which would be important for controlled release as a drug delivery system.

We further determined the stability of the hybridized sequences under oxidative conditions. The oxidized complex, $2_{0 x}$ was incubated with $0.1 \%$ hydrogen peroxide $(30 \mu \mathrm{M})$. Aliquots were analyzed via LC-MS over different time intervals up to 60 min (SI, Figure S11) using SIM detection. Besides monitoring the decrease in the $\mathrm{m} / \mathrm{z}$ of $\mathbf{2}_{\mathrm{ox}}$, SIM also offers the possibility to identify degradation products and allowed us to map the chemical processes involved in the oxidative condition implemented. The SIM profile indicates that no starting material is left after 10 min. We observed complete conversion to compound 3 (Figure $6 \mathrm{~d}$ ). After $10 \mathrm{~min}$, the phenolic compound is further oxidized to the phenol and o-quinone substance forming compound 4, which elutes later due to higher hydrophobicity. This result is not surprising, since 
protected catechols are rather stable against oxidation considering that they are less likely to form oxygen radicals which are crucial in the oxidation process of catechols. ${ }^{32}$ Notably, both sequences remained bound by the disulfide bridge and did not dissociate into the respective single peptide sequences, clearly underlining the stability of the hybridization under tumormimicking oxidative condition.
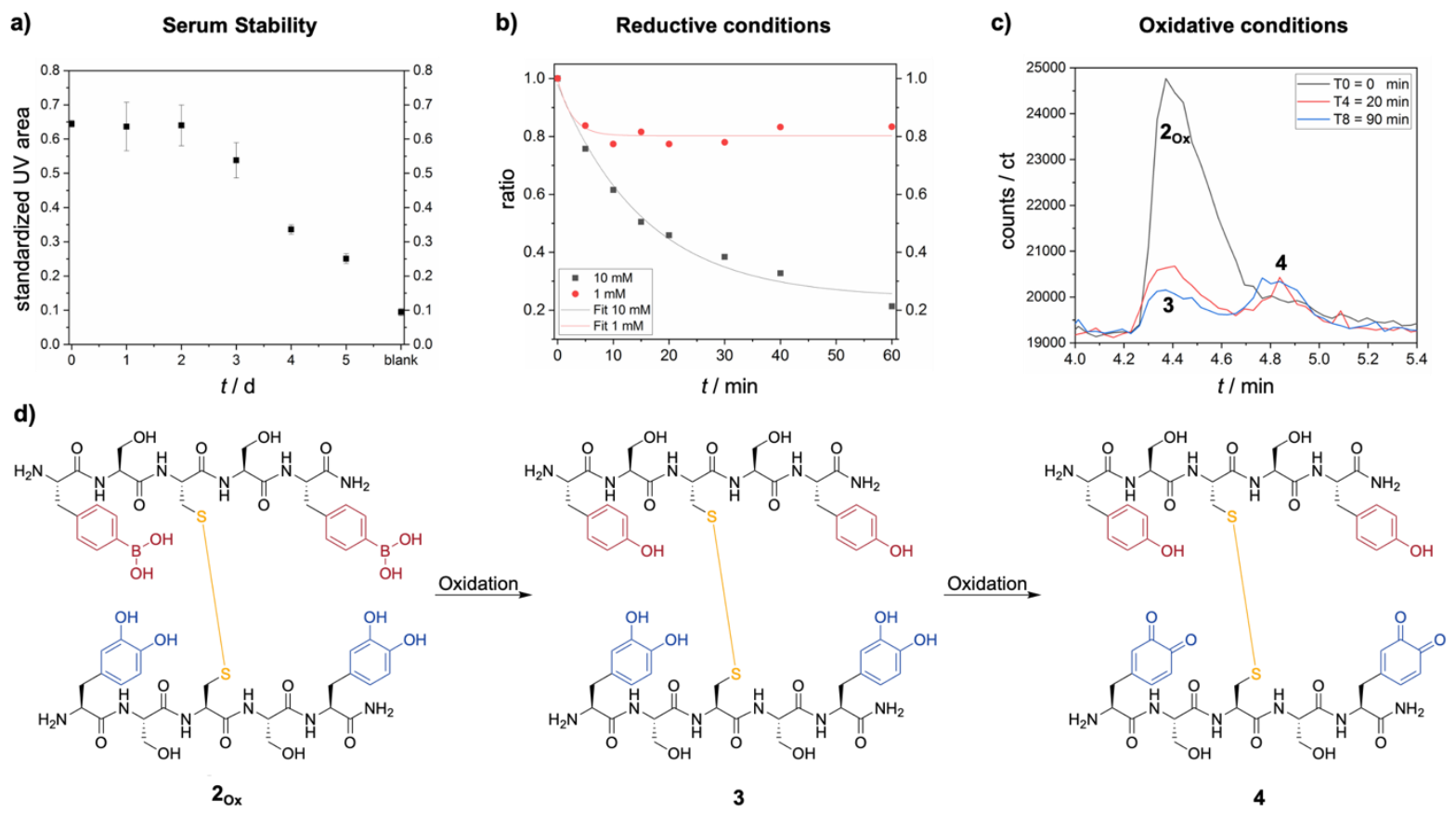

Figure 6: Stability of $20 x$ under different conditions. a) $10 \% \mathrm{FCS}$ at $37^{\circ} \mathrm{C}$. b) Reductive conditions with GSH/GSSG in liver cytosol. c) Oxidative condition with $0.1 \%$ hydrogen peroxide. d) Reaction scheme upon incubation with hydrogen peroxide.

Dynamic covalent tags offer many attractive features for bioconjugate formation as their binding and release could be very useful for the delivery and stimulus-controlled release of drugs. The OSCSO tag was extended with the TAT peptide sequence (YGRKRRQRRR), which is a cell penetrating peptide derived from the human immunodeficiency virus. The TAT sequence has been widely employed for the delivery of cargoes into cells, such as small molecule drugs or proteins. TAT-OSCSO (YGRKRRQRRRS-OSCSO) was synthesized using SPPS and purified by HPLC and identified by MALDI-TOF-MS $\left(m / z=2281.1929[\mathrm{M}+\mathrm{H}]^{+}\right.$, calc. 2281.1955 $\left.[\mathrm{M}+\mathrm{H}]^{+}\right), \mathrm{SI}$, Figure S5). A Dylight488 fluorescence dye (DL488) was conjugated to a BSCSB sequence on the $\mathrm{N}$-terminus as a molecular cargo for transportation by TATOSCSO. DL488-BSCSB was purified by RP-HPLC and identified by ESI-MS (SI, Figure S6). 
The assembly of the dual responsive $T A T \simeq D L 488$ conjugate was performed simply by mixing equal volumes of $2 \mathrm{mM}$ solutions (100 mM phosphate buffer $\mathrm{pH} 7.4$ with $10 \%$ DMSO) of targeting unit (TAT-OSCSO) and the cargo (DL488-BSCSB) and addition of Oxone ${ }^{\circledR}$.

a) Compounds used in this study
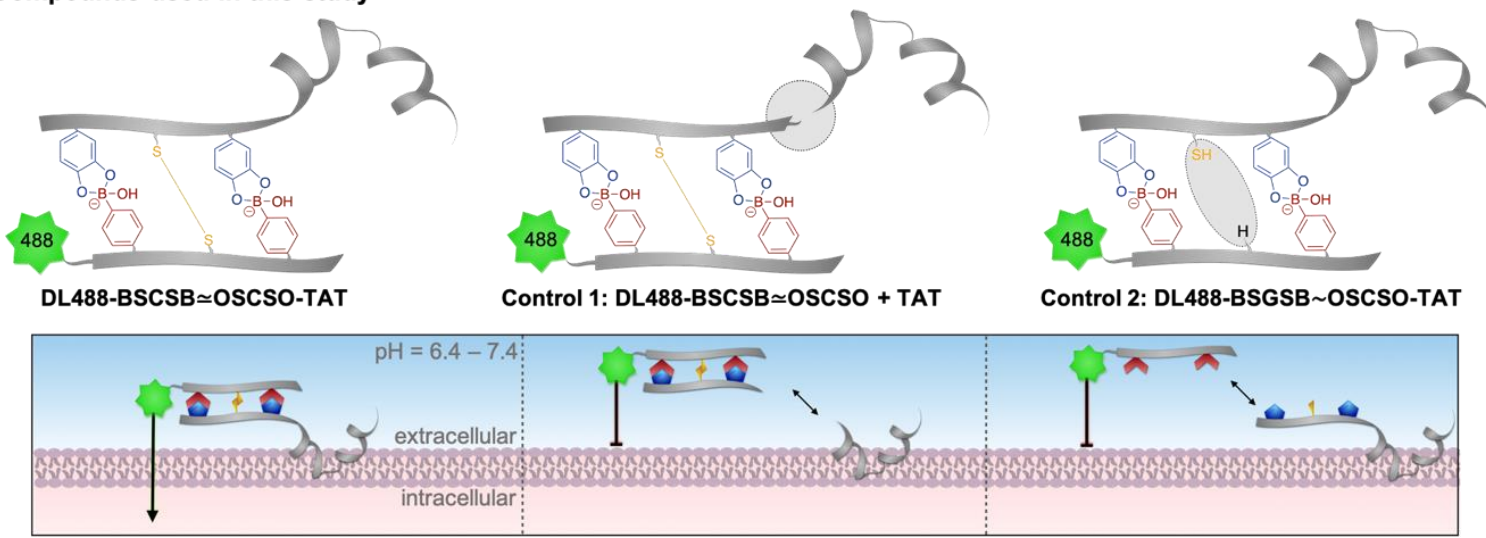

b)
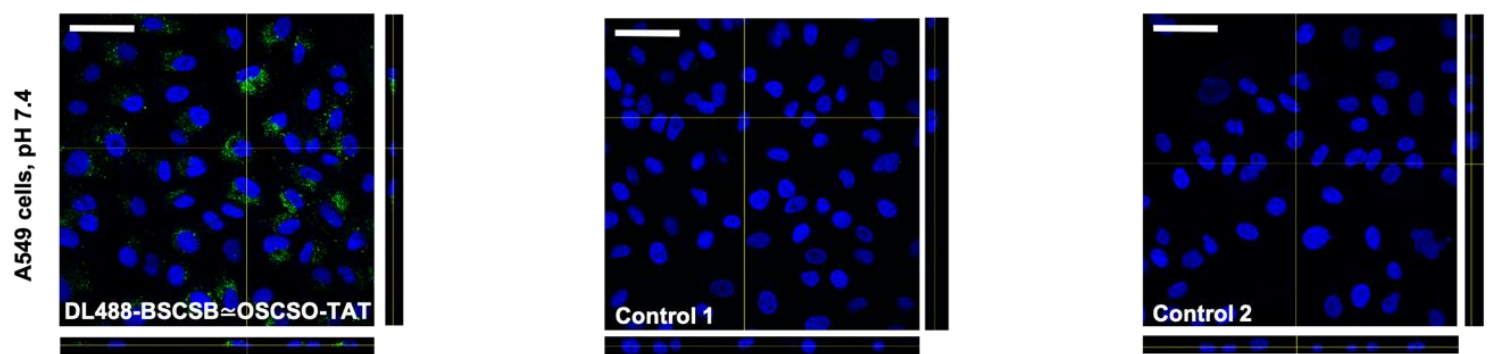

c)
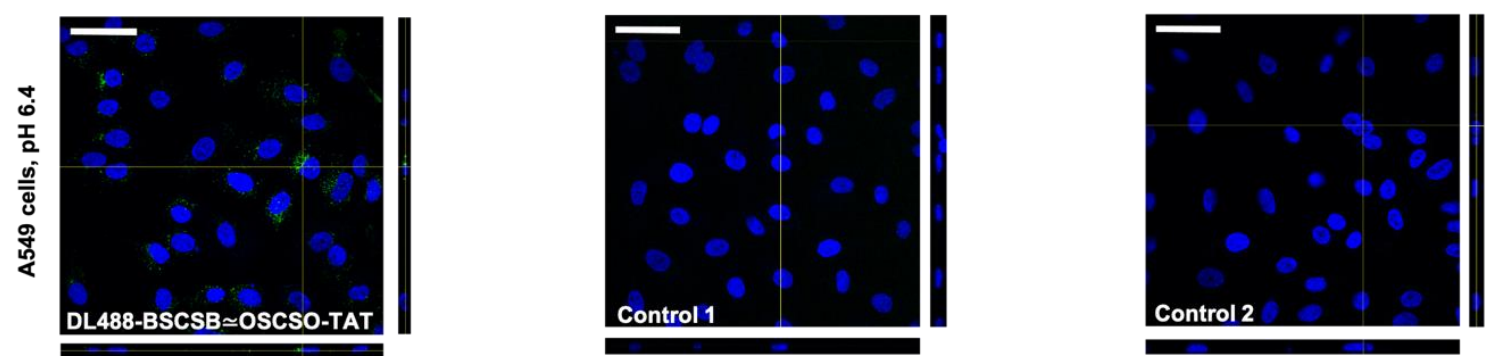

Figure 7: a) Compounds used in this study and schematic overview. (b-c) Representative confocal orthogonal views of DL488 TAT (green) uptake in A549 cells both at b) physiological and c) acidic pH. Internalization is shown in comparison modified compounds (controls 1 and 2) as negative controls. Compounds are applied at concentration of $10 \mu \mathrm{M}$. Cell nuclei are shown in blue by DAPI staining. Scale bar $=50 \mu \mathrm{m}$.

For cell uptake studies, A549 cell line was selected, which is a model of alveolar Type II pulmonary epithelium. ${ }^{33}$ The solution of DL488 $\simeq$ TAT was applied directly to A549 cells to a final concentration of $10 \mu \mathrm{M}$, without any further workup or further purification. As additional controls, (1) a conjugate DL488-BSCSB 0 OSCSO incubated with free TAT sequence and (2) a conjugate without disulfide bridge (DL488-BSGSB) (TAT-OSCSO) where cysteine was replaced with glycine in one of the sequences were both applied at $10 \mu \mathrm{M}$ (Figure 7a). After $24 \mathrm{~h}$, no uptake was observed in the respective controls while DL488 $\simeq$ TAT showed a 
significant uptake (Figure $7 \mathrm{~b}$ ). Taken together, the results proved the immediate assembly of the conjugate and stability both to dilution and incubation in cell medium, as well as TATmediated uptake. Additionally, components of reaction mixture are inert to cells which allows its direct application. Acidosis is a hallmark of the tumor microenvironment and the low extracellular $\mathrm{pH}$ can result in a more invasive phenotype (Figure 7). To verify that the peptide tags are robust even under metastatic tumor-like microenvironment, A549 cancer cells were subjected to stepwise acidification to derive acidic $\mathrm{pH}$-adapted cells at $\mathrm{pH} 6.4 .^{34-36}$ Thereafter DL488 $\simeq$ TAT and the two controls were applied at $10 \mu \mathrm{M}$ for $24 \mathrm{~h}$. Similarly, uptake of DL488 TAT was observed while the two controls were not internalized (Figure 7c).

\section{Conclusion}

By exploiting the cooperative effect of a multivalent, fast dynamic covalent reaction of boronate esters with that of a slower and more stable dynamic disulfide formation, we have overcome the limitation of each chemistry and showed that a robust, reversible system which is dual responsive with tunable binding affinity can be achieved through rational chemical sequence programming. The $\mathrm{pH}$ responsive boronic acid - catechol interaction allows pre-coordination to convert intermolecular to intramolecular thiols of cysteine residues, allowing oxidation to form selectively the heterodimer with significantly reduced reaction time, which offers significant advantage over a single disulfide tag with slower reaction rate and the possibility of disulfide scrambling. The resultant disulfide bond stabilized the conjugate while remaining responsive to a second stimuli - redox environment. Notably, the complementary sequence consisting of two boronate esters is characterized by excellent dissociation constant, outperforming even the binding of single boronic acid with a strong coordinating ligand, i.e. salicylhydroxamate reported previously. ${ }^{13}$ The resultant conjugate is stable under physiological conditions for up to two days and to intracellular oxidative condition, as well as exhibit responsive behavior in tumor-like microenvironment (low $\mathrm{pH}$ or high GSH concentration). This is important for e.g. in vivo application where stability in bloodstream is a major concern, as well as for targeted therapy to avoid unwanted release in normal tissues. Furthermore, very fast conjugation and inertness of the reaction components allows 
preparation of the conjugate directly before application and use in vitro directly without purification. Remarkably, the construct remains stable in acidic extracellular environment of cancer cells due to the presence of the disulfide bridge, enabling internalization. We envisage that the amino acids used in these tags can be expressed in a protein, thus holding immense promise to become a valuable tool in chemistry and biology to grant intelligent systems through the dynamic and stimuli responsive control over protein assembly or peptide/protein-cargo bioconjugates.

\section{ASSOCIATED CONTENT}

Supporting Information.

Full experimental procedures and characterization data are available for new compounds. This material is available free of charge via the Internet at ...

\section{AUTHOR INFORMATION}

${ }^{\nabla}$ Both authors contributed equally in this manuscript

Corresponding Authors

${ }^{*}$ E-mails:

weil@mpip-mainz.mpg.de;

kuan@mpip-mainz.mpg.de.

\section{Funding Sources}

This project has received funding from the European Union's Horizon 2020 research and innovation program under the Marie Skłodowska-Curie grant agreement No 675007, Deutsche Forschungsgemeinschaft (DFG German Research Foundation) - Projektnummer 213555243 - SFB 1066 and Projektnummer 316249678 - SFB 1279

Notes

The authors declare no competing financial interest. 
M. M. Zegota thanks the Marie Curie International Training Network Protein Conjugates under grant agreement No 675007 for a research scholarship. The authors are grateful to the Max Planck Society, German National Foundation (SFB 1066 (project Q5 and B16), SFB 1279 (project C1) and the Marie Skłodowska-Curie Actions (MSCA) for the financial support.

J. A. S. Coelho thanks the Fundação para a Ciência e a Tecnologia (FCT) for Scientific Employment Stimulus 2020/02383/CEECIND.

ABBREVIATIONS

CA, catechol; BA, boronic acid

\section{REFERENCES}

(1) He, Q.; Chen, J.; Yan, J.; Cai, S.; Xiong, H.; Liu, Y.; Peng, D.; Mo, M.; Liu, Z. Tumor Microenvironment Responsive Drug Delivery Systems. Asian J. Pharm.

Sci. 2020, 15 (4), 416-448. https://doi.org/10.1016/j.ajps.2019.08.003.

(2) Wang, S.; Yu, G.; Wang, Z.; Jacobson, O.; Tian, R.; Lin, L. Sen; Zhang, F.; Wang, J.; Chen, X. Hierarchical Tumor Microenvironment-Responsive Nanomedicine for Programmed Delivery of Chemotherapeutics. Adv. Mater. 2018, 30 (40), 1803926. https://doi.org/10.1002/adma.201803926.

(3) Kuan, S. L.; Fischer, S.; Hafner, S.; Wang, T.; Syrovets, T.; Liu, W.; Tokura, Y.; Ng, D. Y. W.; Riegger, A.; Förtsch, C.; Jäger, D.; Barth, T. F. E.; Simmet, T.; Barth, H.; Weil, T. Boosting Antitumor Drug Efficacy with Chemically Engineered Multidomain Proteins. Adv. Sci. 2018, 5 (8), 1701036. https://doi.org/10.1002/advs.201701036.

(4) Wang, T.; Ng, D. Y. W.; Wu, Y.; Thomas, J.; Tam Tran, T.; Weil, T. Bis-Sulfide Bioconjugates for Glutathione Triggered Tumor Responsive Drug Release.

Chem. Commun. 2014, 50 (9), 1116-1118.

https://doi.org/10.1039/c3cc47003b. 
(5) Webber, M. J.; Langer, R. Drug Delivery by Supramolecular Design. Chem. Soc. Rev. 2017, 46 (21), 6600-6620. https://doi.org/10.1039/C7CS00391A.

(6) Jin, Y.; Yu, C.; Denman, R. J.; Zhang, W. Recent Advances in Dynamic Covalent Chemistry. Chem. Soc. Rev. 2013, 42 (16), 6634-6654. https://doi.org/10.1039/c3cs60044k.

(7) Ulrich, S. Growing Prospects of Dynamic Covalent Chemistry in Delivery Applications. Acc. Chem. Res. 2019, 52 (2), 510-519. https://doi.org/10.1021/acs.accounts.8b00591.

(8) Akgun, B.; Hall, D. G. Boronic Acids as Bioorthogonal Probes for Site-Selective Labeling of Proteins. Angew. Chem. Int. Ed. 2018, 57 (40), 13028-13044. https://doi.org/10.1002/anie.201712611.

(9) António, J. P. M.; Russo, R.; Carvalho, C. P.; Cal, P. M. S. D.; Gois, P. M. P. Boronic Acids as Building Blocks for the Construction of Therapeutically Useful Bioconjugates. Chem. Soc. Rev. 2019, 48 (13), 3513-3536. https://doi.org/10.1039/C9CS00184K.

(10) Bandyopadhyay, A.; Cambray, S.; Gao, J. Fast and Selective Labeling of NTerminal Cysteines at Neutral PH via Thiazolidino Boronate Formation. Chem. Sci. 2016, 7 (7), 4589-4593. https://doi.org/10.1039/C6SC00172F.

(11) Darko, A.; Wallace, S.; Dmitrenko, O.; Machovina, M. M.; Mehl, R. A.; Chin, J. W.; Fox, J. M. Conformationally Strained Trans-Cyclooctene with Improved Stability and Excellent Reactivity in Tetrazine Ligation. Chem. Sci. 2014, 5 (10), 3770-3776. https://doi.org/10.1039/c4sc01348d.

(12) Ramsay, W. J.; Bayley, H. Single-Molecule Determination of the Isomers of dGlucose and d-Fructose That Bind to Boronic Acids. Angew. Chem. Int. Ed. 
2018, 57 (11), 2841-2845. https://doi.org/10.1002/anie.201712740.

(13) Zegota, M. M.; Wang, T.; Seidler, C.; Wah Ng, D. Y.; Kuan, S. L.; Weil, T. "Tag and Modify" Protein Conjugation with Dynamic Covalent Chemistry. Bioconjug. Chem. 2018, 29 (8), 2665-2670.

https://doi.org/10.1021/acs.bioconjchem.8b00358.

(14) Ng, D. Y. W.; Arzt, M.; Wu, Y.; Kuan, S. L.; Lamla, M.; Weil, T. Constructing Hybrid Protein Zymogens through Protective Dendritic Assembly. Angew. Chem. Int. Ed. 2014, 53 (1), 324-328. https://doi.org/10.1002/anie.201308533.

(15) Lopes, R. M. R. M.; Ventura, A. E.; Silva, L. C.; Faustino, H.; Gois, P. M. P. N,O-Iminoboronates: Reversible Iminoboronates with Improved Stability for Cancer Cells Targeted Delivery. Chem. - Eur. J. 2018, 24 (48), 12495-12499. https://doi.org/10.1002/chem.201802515.

(16) Lu, J.; Jiang, F.; Lu, A.; Zhang, G. Linkers Having a Crucial Role in AntibodyDrug Conjugates. Int. J. Mol. Sci. 2016, 17 (4), 561. https://doi.org/10.3390/ijms17040561.

(17) Kölmel, D. K.; Kool, E. T. Oximes and Hydrazones in Bioconjugation: Mechanism and Catalysis. Chem. Rev. 2017, 117 (15), 10358-10376. https://doi.org/10.1021/acs.chemrev.7b00090.

(18) Bargh, J. D.; Isidro-Llobet, A.; Parker, J. S.; Spring, D. R. Cleavable Linkers in Antibody-Drug Conjugates. Chem. Soc. Rev. 2019, 48 (16), 4361-4374. https://doi.org/10.1039/C8CS00676H.

(19) Dirksen, A.; Dirksen, S.; Hackeng, T. M.; Dawson, P. E. Nucleophilic Catalysis of Hydrazone Formation and Transimination: Implications for Dynamic Covalent Chemistry. J. Am. Chem. Soc. 2006, 128 (49), 15602-15603. 
https://doi.org/10.1021/ja067189k.

(20) Dirksen, A.; Hackeng, T. M.; Dawson, P. E. Nucleophilic Catalysis of Oxime Ligation. Angew. Chem. Int. Ed. 2006, 45 (45), 7581-7584. https://doi.org/10.1002/anie.200602877.

(21) Hioki, H.; Clark Still, W. Chemical Evolution: A Model System That Selects and Amplifies a Receptor for the Tripeptide (D)Pro(L)Val(D)Val. J. Org. Chem. 1998, 63 (4), 904-905. https://doi.org/10.1021/jo971782q.

(22) Schäfer, O.; Barz, M. Of Thiols and Disulfides: Methods for Chemoselective Formation of Asymmetric Disulfides in Synthetic Peptides and Polymers.

Chem. - A Eur. J. 2018, 24 (47), 12131-12142.

https://doi.org/10.1002/chem.201800681.

(23) Martínez-Aguirre, M. A.; Flores-Alamo, M.; Yatsimirsky, A. K. Thermodynamic and Structural Study of Complexation of Phenylboronic Acid with Salicylhydroxamic Acid and Related Ligands. Appl. Organomet. Chem. 2018, 32 (8), e4405. https://doi.org/10.1002/aoc.4405.

(24) Han, G. S.; Domaille, D. W. Tuning the Exchange Dynamics of Boronic Acid Hydrazones and Oximes with PH and Redox Control. Org. Biomol. Chem. 2021. https://doi.org/10.1039/D1OB00191D.

(25) Leguizamon, S. C.; Dunn, M.; Scott, T. F. Sequence-Directed Dynamic Covalent Assembly of Base-4-Encoded Oligomers. Chem. Commun. 2020, 56 (56), 7817-7820. https://doi.org/10.1039/d0cc01083a.

(26) Hebel, M.; Riegger, A.; Zegota, M. M.; Kizilsavas, G.; Gačanin, J.; Pieszka, M.; Lückerath, T.; Coelho, J. A. S.; Wagner, M.; Gois, P. M. P.; Ng, D. Y. W.; Weil, T. Sequence Programming with Dynamic Boronic Acid/Catechol Binary Codes. 
J. Am. Chem. Soc. 2019, 141 (36), 14026-14031.

https://doi.org/10.1021/jacs.9b03107.

(27) Parida, K. N.; Chandra, A.; Moorthy, J. N. Oxidation of Thiols to Sulphonic Acids with $\mathrm{Oxone} \circledast / \mathrm{NaHCO} 3$ and $\mathrm{KBrO}$. ChemistrySelect 2016, 1 (3), 490494. https://doi.org/10.1002/slct.201600028.

(28) Springsteen, G.; Wang, B. A Detailed Examination of Boronic Acid-Diol Complexation. Tetrahedron 2002, 58 (26), 5291-5300. https://doi.org/10.1016/S0040-4020(02)00489-1.

(29) Liu, S.; Ono, R. J.; Yang, C.; Gao, S.; Ming Tan, J. Y.; Hedrick, J. L.; Yang, Y. Y. Dual PH-Responsive Shell-Cleavable Polycarbonate Micellar Nanoparticles for in Vivo Anticancer Drug Delivery. ACS Appl. Mater. Interfaces 2018, 10 (23), 19355-19364. https://doi.org/10.1021/acsami.8b01954.

(30) Wang, X.; Cai, X.; Hu, J.; Shao, N.; Wang, F.; Zhang, Q.; Xiao, J.; Cheng, Y. Glutathione-Triggered "off-On" Release of Anticancer Drugs from DendrimerEncapsulated Gold Nanoparticles. J. Am. Chem. Soc. 2013, 135 (26), 98059810. https://doi.org/10.1021/ja402903h.

(31) Wang, T.; Ng, D. Y. W.; Wu, Y.; Thomas, J.; Tam Tran, T.; Weil, T. Bis-Sulfide Bioconjugates for Glutathione Triggered Tumor Responsive Drug Release. Chem. Commun. 2014, 50 (9), 1116-1118. https://doi.org/10.1039/c3cc47003b.

(32) Pillar-Little, E. A.; Guzman, M. I. Oxidation of Substituted Catechols at the AirWater Interface: Production of Carboxylic Acids, Quinones, and Polyphenols. Environ. Sci. Technol. 2017, 51 (9), 4951-4959. https://doi.org/10.1021/acs.est.7b00232. 
(33) Foster, K. A.; Oster, C. G.; Mayer, M. M.; Avery, M. L.; Audus, K. L. Characterization of the A549 Cell Line as a Type II Pulmonary Epithelial Cell Model for Drug Metabolism. Exp. Cell Res. 1998, 243 (2), 359-366. https://doi.org/10.1006/excr.1998.4172.

(34) Wojtkowiak, J. W.; Rothberg, J. M.; Kumar, V.; Schramm, K. J.; Haller, E.; Proemsey, R. J.; Lee, H.; Lloyd, M. C.; Sloane, B. F.; Gillies, R. J.. Chronic Autophagy Is a Cellular Adaptation to Tumor Acidic PH Microenvironments Cancer Res 2012, 72 (16), 3938-3947. https://doi.org/10.1158/00085472.CAN-11-3881.

(35) Mendoza, E. E.; Pocceschi, M. G.; Kong, X.; Leeper, D. B.; Caro, J.; Limesand, K. H.; Burd, R. Control of Glycolytic Flux by AMP-Activated Protein Kinase in Tumor Cells Adapted to Low Ph1. Transl. Oncol. 2012, 5 (3), 208-216. https://doi.org/10.1593/tlo.11319.

(36) Sutoo, S.; Maeda, T.; Suzuki, A.; Kato, Y. Adaptation to Chronic Acidic Extracellular PH Elicits a Sustained Increase in Lung Cancer Cell Invasion and Metastasis. Clin. Exp. Metastasis 2020, 37 (1), 133-144. https://doi.org/10.1007/s10585-019-09990-1. 